\title{
¿Observations of Turbulence Caused by a Combination of Tides and Mean Baroclinic Flow over a Fjord Sill
}

\author{
ANDRE STAALSTRØM \\ Section for Biogeochemistry and Physical Oceanography, Norwegian Institute for Water Research, and \\ Department of Geosciences, University of Oslo, Oslo, Norway \\ LARS ARNEBORG AND BENGT LiLJEBLADH \\ Department of Earth Sciences, University of Gothenburg, Gothenburg, Sweden \\ GÖRAN BROSTRÖM \\ Department of Earth Sciences, University of Gothenburg, Gothenburg, Sweden, and Division for \\ Oceanography and Marine Meteorology, Norwegian Meteorological Institute, Oslo, Norway
}

(Manuscript received 13 September 2013, in final form 23 September 2014)

\begin{abstract}
This study investigates the dissipation rates and flow conditions at the Drøbak Sill in the Oslofjord. The area was transected 13 times with a free-falling microstructure shear probe during 4 days in June 2011. At the same time, an ADCP was deployed inside the sill. During most tidal cycles, internal hydraulic jumps with high dissipation rates were found on the downstream side of the sill. However, the internal response varied strongly between different tidal cycles with similar barotropic forcing. In the beginning of the observational period, ebb tides had no hydraulic jumps, and in the end one of the flood tides did not have a hydraulic jump. During the same period, the mean baroclinic exchange flow changed from inflow to outflow in the bottom layer. The authors conclude that the conditions at the sill are on the edge of forming hydraulic jumps and that the mean baroclinic exchange may push the flow above or below the limit of a hydraulic jump depending on the situation. This conclusion is supported by two-layer hydraulic theory. The volume-integrated dissipation rates within $500 \mathrm{~m}$ from the sill crest compare well with estimates of energy loss in the lower layer calculated from the Bernoulli drop under the assumption of no energy loss in the upper layer. Finally, the mean dissipation rate at the sill was compared with the radiation of internal tidal energy away from the sill, and it was found that about $60 \%-90 \%$ of the total energy loss was dissipated locally.
\end{abstract}

\section{Introduction}

Flow-topography interactions caused by stratified flow over, around, and through rough topography are important for mixing in the deep abyssal ocean (e.g., Ledwell et al. 2000), over the shelf (e.g., Nash and Moum 2001), and in fjords (e.g., Arneborg and Liljebladh 2009). Fjord entrances with sills are typical locations of strong flowtopography interactions due to strong barotropic and

๑ Denotes Open Access content.

Corresponding author address: Andre Staalstrøm, Norwegian Institute for Water Research, Gaustadalleen 21, 0349 Oslo, Norway. E-mail: ans@niva.no baroclinic currents caused by tides and exchange processes between the fjord and the coastal water (e.g., Arneborg 2004). Barotropic tides can lose energy to turbulence locally at the sill through bottom friction, formation of downstream jets with separation from the sides, and through formation of internal hydraulic jumps. They can also lose energy to internal tides, internal lee waves, and other internal waves that may propagate away and transfer energy to turbulence and mixing elsewhere (e.g., Klymak and Gregg 2004; Inall et al. 2005). Although detailed studies have been performed in some fjords, knowledge is still missing about when different processes are important and how much mixing they cause and where. The feature that can be most successfully modeled is probably the internal tide generation, where simple two-layer (Stigebrandt 1976, 1999) or 
continuous stratification (Stacey 1984) models tend to give results of the correct order of magnitude for the energy propagation into fjords (e.g., Stacey 1984; Klymak and Gregg 2004; Arneborg and Liljebladh 2009).

Stigebrandt and Aure (1989) proposed that the barotropic energy loss at the sill is dominated by internal tide generation when the Froude number

$$
\mathrm{Fr}=v_{s} / c_{1}
$$

is less than one (so-called wave fjords) and that jets dominate for $\mathrm{Fr}>1$ (jet fjords). Here, $v_{s}$ is the barotropic tidal velocity amplitude over the sill, and $c_{1}$ is the phase speed of the first internal wave mode in the deep water away from the sill. However, observations indicate that both the local energy loss at the sill and internal tide generation are important for Fr ranging from small values (Arneborg and Liljebladh 2009) to values close to and above one (Klymak and Gregg 2004; Inall et al. 2005). Stashchuk et al. (2007) reveal strong baroclinic wave response in the Scottish Loch Etive, where Fr is much higher than 1 at the sill crest, and it is shown that the origin of these waves is at a deeper part of the sill, away from the sill crest, where Fr is less than one. However, note that $\mathrm{Fr}=1$ is not a good indication for critical conditions at the sill, since the internal wave velocity is not given by $c_{1}$ in the presence of strong shear and local depth changes over the sill that are caused by nonlinearity of the flow.

A more relevant Froude number for two-layer flow is the composite Froude number (e.g., Farmer and Denton 1985) defined as

$$
G^{2}=\mathrm{Fr}_{1}^{2}+\mathrm{Fr}_{2}^{2},
$$

where

$$
\mathrm{Fr}_{i}^{2}=\frac{\rho_{2}}{\rho_{2}-\rho_{1}} \frac{v_{i}^{2}}{g h_{i}}, \quad i=1,2
$$

The $\rho_{i}$ are the densities, $v_{i}$ are the velocities, $h_{i}$ are the thicknesses for the upper $(i=1)$ and lower $(i=2)$ layers, and $g$ is the gravitational acceleration. Under the assumption of a rigid lid at the surface, the propagation speed of one of the two long internal wave solutions vanishes when $G^{2}=1$, which is called critical flow. This means that long internal waves can propagate in both directions for $G^{2}<1$ (subcritical flow), while they can only travel in one direction for $G^{2}>1$ (supercritical flow). Then, if the fjord width is constant, the flow can only change smoothly from subcritical to supercritical conditions when the bottom slope is zero, for example, at the sill crest, where it is then said to be hydraulically controlled (e.g., Armi 1986). Hydraulic jumps occur

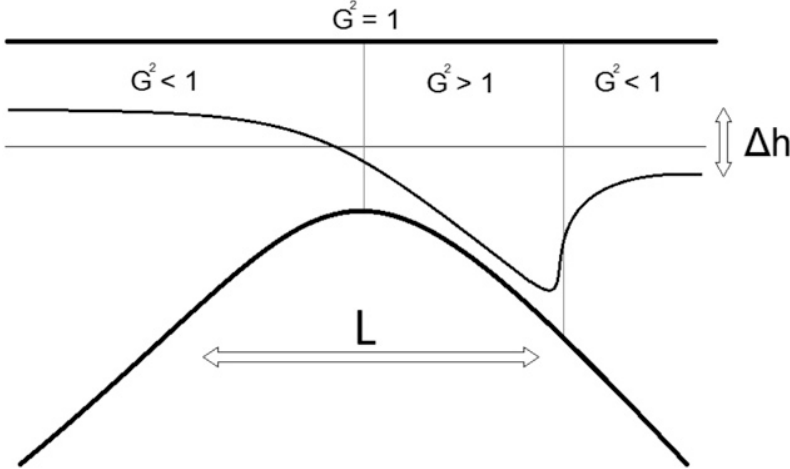

FIG. 1. Sketch of a hydraulically controlled two-layer flow over a sill. The flow is from left to right. The horizontal length scale of the sill is $L$. The vertical drop in the interface is $\Delta h$.

when the flow over the sill is strong enough to create controlled flow at the sill, thus the supercritical flow on one side of the sill must somehow adjust to the subcritical flow further away from the sill, which happens in a dissipative jump (Fig. 1) (e.g., Baines 1995).

Tidal flow is not steady, but if the tidal particle orbit $v_{s} / \omega$, where $\omega$ is the angular frequency of the tide, is long compared with the length scale $L$, we may assume that the steady hydraulic theory gives reasonable predictions of some basic features of the flow. In Knight Inlet, the observed jump tends to develop slower than predicted by two-dimensional primitive equation model results, where the flow causes an internal lee wave that quickly breaks (Cummins 2000). The observed slow response was first explained by the importance of flow separation and small-scale entrainment for flow development (Farmer and Armi 1999; Cummins 2000). Later it was argued (Afanasyev and Peltier 2001; Klymak and Gregg 2001, 2003) that three-dimensional effects and a downstream density pool rather than small-scale processes could explain the differences between observations and models.

If baroclinic mean currents are superposed on the barotropic tides, this may be expected to influence the occurrence of critical conditions at the sill. For two-layer flow over a sill, which is subcritical upstream of the sill, only the bottom layer will be accelerated over the sill crest and dominate $G$ there (e.g., Armi 1986). Therefore, one may assume that a baroclinic mean current in the bottom layer will tend to increase $G$ when it is in the same direction as the tidal orbital velocity and decrease $G$ during the rest of the tidal phases.

In the present work, we analyze detailed microstructure transects through internal hydraulic jumps at the Drøbak Sill of the Oslofjord. The Drøbak Sill with a depth of $20 \mathrm{~m}$ is the main sill of the Oslofjord, separating the 150-m-deep inner basins from the deep outer parts of the fjord (Fig. 2). Although the tides are relatively weak 


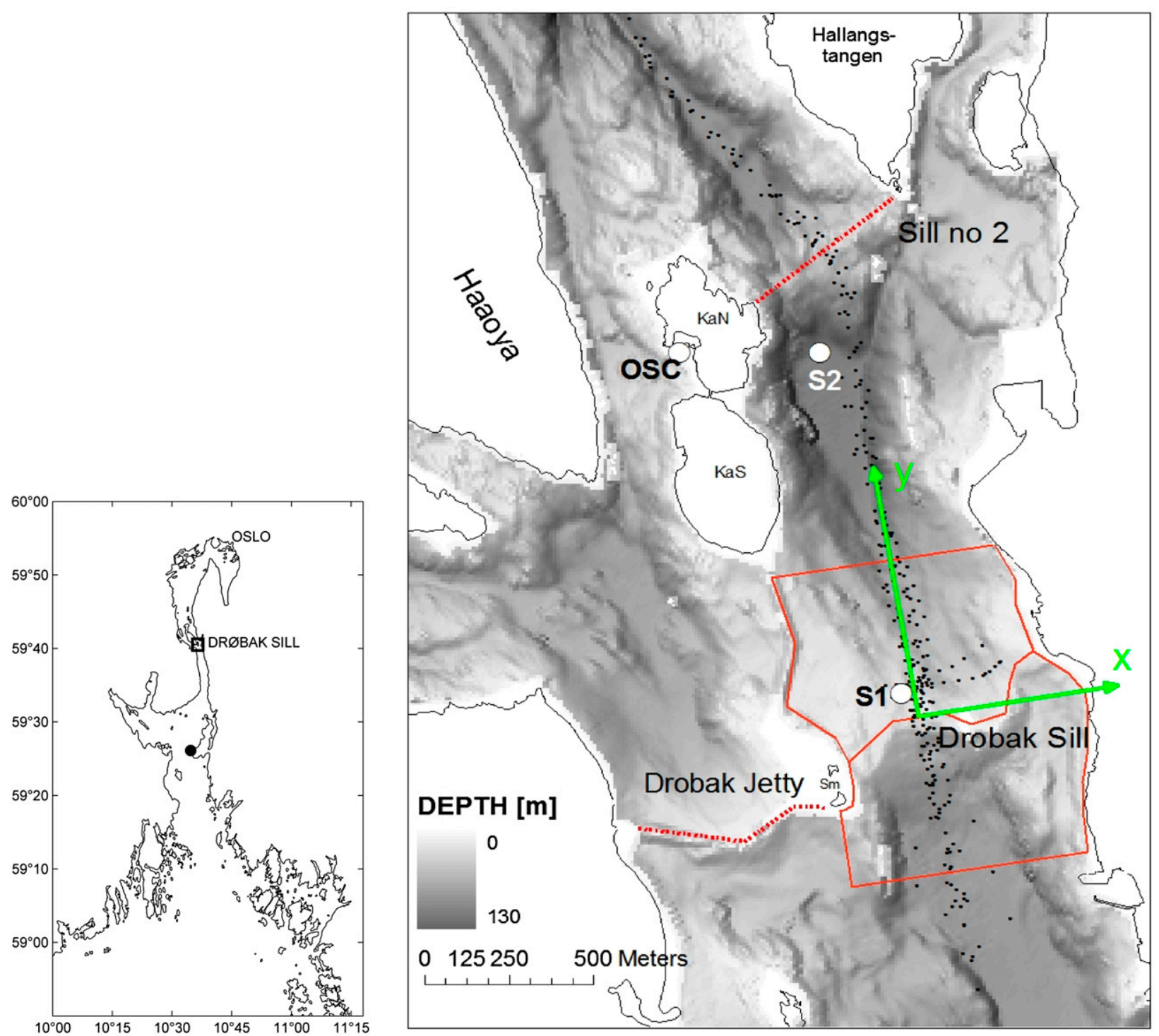

FIG. 2. (a) Map of the Oslofjord. The black dot is the meteorological station Gulholmen. (b) Map of the area around the Drøbak Sill. White circles are the ADCP moorings. MSS stations are marked with black dots. Sea level is recorded at station Oscarsborg (OSC; white circle) operated by the Norwegian Hydrological Survey. The area $500 \mathrm{~m}$ north and south of the Drøbak Sill is our focus area and is indicated with red lines, and the coordinate system used in the calculations is indicated with green arrows. Bathymetric data are from the Geological Survey of Norway (Lepland et al. 2009). A grayscale indicates the depths down to $130 \mathrm{~m}$. A hillside shade effect is used to emphasize the bathymetric structure. The subsurface Drøbak Jetty runs from Kaholmen south (KaS) to Småskjær (Sm) and further to the mainland on the west side of the sound and is marked with a red dashed line. The Drøbak Sill $(20 \mathrm{~m})$ is located between Småskjær and Drøbak. There is a second sill $(47 \mathrm{~m})$ between Kaholmen north $(\mathrm{KaN})$ and the southern tip of Hallangstangen, marked with a red dashed line.

$(\approx 0.15$-m semidiurnal tidal amplitude), the barotropic current amplitude over the sill is about $v_{s}=0.4 \mathrm{~m} \mathrm{~s}^{-1}$. With a mode- 1 phase speed of about $c_{1}=0.9 \mathrm{~m} \mathrm{~s}^{-1}$ (Staalstrøm et al. 2012), the resulting Froude number $\mathrm{Fr} \approx 0.45$ is well below one implying wave-fjord conditions as defined by Stigebrandt and Aure (1989). Nevertheless, we observe hydraulic jumps in this study. In comparison, the Froude numbers are $\mathrm{Fr} \approx 0.75$ in Knight Inlet (Stigebrandt 1999) and $\mathrm{Fr} \approx 1.8$ in Loch Etive (Inall et al.
2004). The length scale of the Drøbak Sill is about $500 \mathrm{~m}$, which is much less than the tidal orbital amplitude $\left(v_{s} / \omega \approx\right.$ $2900 \mathrm{~m}$ ), and we expect quasi-steady hydraulic theory to be valid over this sill.

The main focus of the present study is to investigate the structure of internal hydraulic jumps and associated dissipation rates of turbulent kinetic energy over the Drøbak Sill, the partition of the barotropic energy loss at the sill, and how mean baroclinic currents over the sill 
influence the hydraulic jumps. The instrument setup and the principle behind calculations of the dissipation rate are briefly described in section 2 . In section 3 , we present the data, starting with ADCP data and repeated microstructure transects over the sill from June 2011, continuing with examples of ADCP data at the sill from 2009. We then present estimates of integrated dissipation rates in the sill region, estimates of energy loss in the lower layer based on the Bernoulli function, and comparison with the velocity in the lower layer at the sill. Finally, the results are discussed in section 4.

\section{Methods}

\section{a. Dataset}

In this paper, we present a combination of observations of currents at fixed positions and vertical profiles of stratification and dissipation rates of turbulent kinetic energy along transects. The data were mainly collected during the period 20 to 23 June 2011 on board the Research Vessel (R/V) Trygve Braarud. The wind conditions were relatively calm during the data collection. The maximum measured wind speed at station Gullholmen $\left(59^{\circ} 26.11^{\prime} \mathrm{N}, 10^{\circ} 34.68^{\prime} \mathrm{E}\right)$ was $8.4 \mathrm{~m} \mathrm{~s}^{-1}$. A microstructure shear profiler (MSS90L, hereinafter MSS) was dropped continuously from the stern of the ship as it cruised at low speeds $(\approx 1 \mathrm{kt})$. The MSS90L is a loosely tethered profiler with standard conductivity, temperature, and pressure (CTD) sensors as well as two airfoil shear probes (PNS06) sampling at $1024 \mathrm{~Hz}$, while the profiler is descending vertically with a speed of $0.6-$ $0.7 \mathrm{~m} \mathrm{~s}^{-1}$. A more detailed discussion of an earlier version of the instrument can be found in Prandke and Stips (1998). A sensor protection guard allows profiling down to the bottom (with sensors $0.1 \mathrm{~m}$ above bottom). The data from the upper 2-3 $\mathrm{m}$ that were influenced by vessel turbulence was removed. A total of 15 transects were performed; 13 along-fjord transects over the Drøbak Sill and 2 across-fjord transects just inside the sill. Altogether we collected 368 profiles, and the positions of these profiles are shown as black dots in Fig. 2. The times of the transects are indicated in Fig. 3a as gray bars on top of the sea level (SL) measured at Oscarsborg.

An upward-looking acoustic Doppler current profiler (ADCP; Nortek Continental $190 \mathrm{kHz}$ ) was deployed at $100-\mathrm{m}$ depth at station $\mathrm{S} 2\left(59^{\circ} 40.67^{\prime} \mathrm{N}, 10^{\circ} 36.71^{\prime} \mathrm{E}\right)$ before the first MSS transect in 2011 and recovered after the last transect. The current profiler provided reliable data between 10.5- and 94.5-m depths with a resolution of $3 \mathrm{~m}$ in depth and $10 \mathrm{~min}$ in time.

We also utilize two ADCP datasets from September 2009, when upward-looking ADCPs were deployed at station S1 (RDI600) and at station S2 (Nortek Continental
$190 \mathrm{kHz})$. The ADCP at station S1 $\left(59^{\circ} 40.08^{\prime} \mathrm{N}\right.$, $10^{\circ} 36.94^{\prime} \mathrm{E}$ ) was deployed at the bottom just inside the sill crest at 23-m depth. The vertical resolution was $1 \mathrm{~m}$ between 2.5- and 21.5-m depths. At station S2 the setup was the same as in 2011.

\section{b. Analyses}

Dissipation rates of turbulent kinetic energy were obtained from the microstructure shear data using standard methods, as described in more detail by, for example, Arneborg and Liljebladh (2009). The shear probes measure how one transverse velocity component changes along the path of the profiler. From the shear variance, one can calculate the dissipation rate under the assumption of isotropic turbulence. However, since the sensors do not cover the complete wavenumber range of the shear variance, the dissipation rates are obtained by fitting the observed shear spectrum to the universal Nasmyth spectrum for that component. This is done in 50\% overlapping 512-point segments, and the resulting estimates of the dissipation rate are averaged into 1-m bins.

In the present case, the main problem with this method is that the velocity of the sensor tip through the water is estimated from the rate of change of the pressure. The velocity through the water enters the calculation of dissipation rates to the power of 4 , so small errors in the velocity give considerable errors in the dissipation rate. As discussed in Klymak and Gregg (2004), this may cause a large problem in a hydraulic jump where the vertical velocities can be large relative to the sinking velocity of the profiler. As proposed by Klymak and Gregg (2004), we also considered a constant velocity rather than that calculated from the pressure. However, except for one extreme case with small fall velocity $\left(0.3 \mathrm{~m} \mathrm{~s}^{-1}\right)$ near the bottom, which was removed, we found no large differences doing this ( $<15 \%$ in integrated dissipation). Considering that the fall velocity may also be influenced by other effects, for example, strong shear and density changes, we did not find it justifiable to use anything else than the standard method in this case.

\section{Results}

In this section, we will first present results from the moored instruments at station S2, followed by results from the dissipation measurements. Based on these data, we present current measurements at the sill from 2009 and both composite and layerwise Froude number estimates. Finally, we integrate the dissipation rates and compare the total dissipation rates with the energy loss in the lower layer estimated from Bernoulli drops. In the following all times are local times (UTC $+2 \mathrm{~h}$ ). 
a)

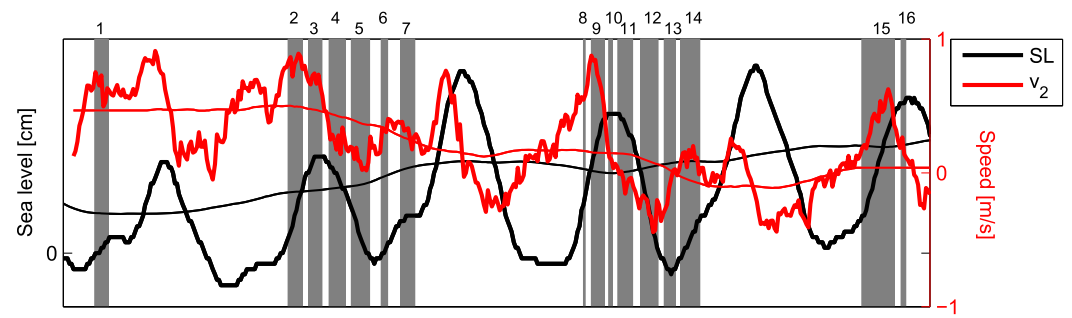

b)

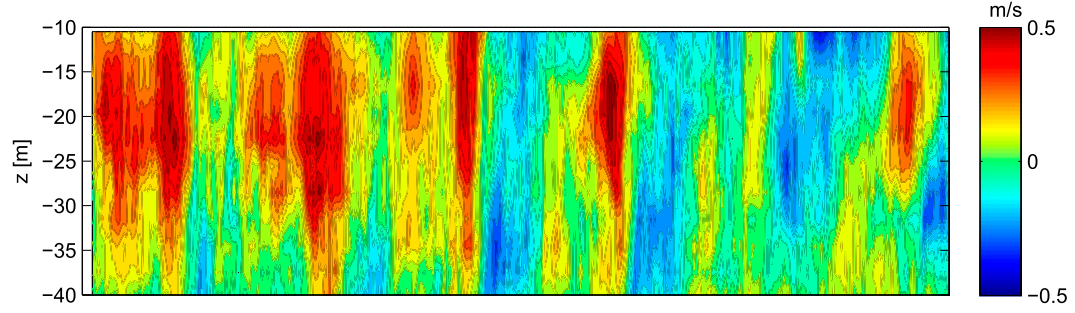

c)

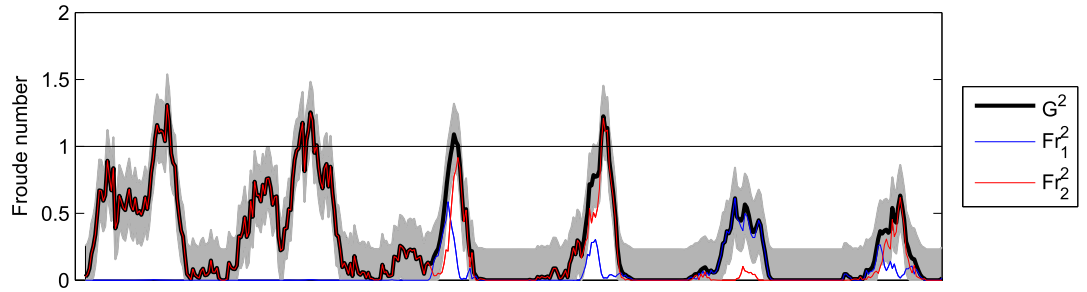

d)

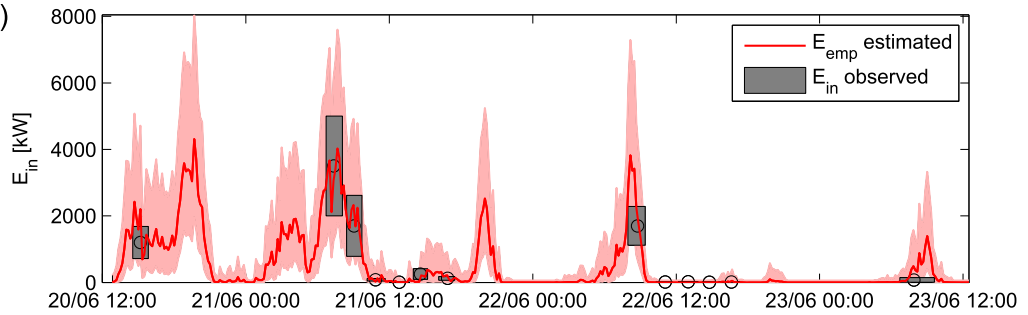

FIG. 3. (a) SL measured by the Hydrographic Service of the Norwegian Mapping Authority at the tide gauge station of Oscarsborg (Fig. 2) plotted with a bold black line and the estimated flow in the lower layer over the sill $v_{2}$ in bold red. The mean sea level and mean flow, constructed by taking the running mean over a tidal period, is plotted as thin lines, in black and red, respectively. Each MSS transect is marked with gray shading. (b) Observed current along the fjord at station S2. The color scale indicates current speed in $\mathrm{m} \mathrm{s}^{-1}$. Red colors indicate currents into the fjord (flood) and blue out of the fjord (ebb). (c) Estimated composite and layerwise Froude numbers at the sill based on current and sea level measurements at station S2. The gray shading indicates the error range for $G^{2}$. (d) Integrated dissipation based on direct measurements (gray bars) and estimated from (6) (red line). The pink shading indicates the error range for $E_{\mathrm{emp}}$.

\section{a. Mooring data at $S 2$ in 2011}

During the field study, the sea level variations were dominated by a semidiurnal tidal signal with a range of about $0.3 \mathrm{~m}$ superposed by a higher harmonic (Fig. 3a). It has earlier been found that the shape of the tidal curve in the Oslofjord is well described by the sum of a semidiurnal and a quarter-diurnal tidal constituent (Tryggestad 1974). This is often seen as two distinct maxima during the flood current (cf. Fig. 3b) at station S2 inside the Drøbak Sill. It is also notable that the flood currents are generally strong (up to about $0.5 \mathrm{~m} \mathrm{~s}^{-1}$ at
S2) and concentrated in the depth range of $15-30 \mathrm{~m}$ inside the sill (which is around the sill depth of $20 \mathrm{~m}$ ), while the ebb currents are weaker and much more uniformly distributed in depth.

The subtidal velocities in the observed depth range (below $10.5 \mathrm{~m}$ ) are positive into the fjord in the beginning of the observation period and negative in the end of the period. The barotropic velocities corresponding to the observed detided sea level variations (Fig. 3a) are less than $1 \mathrm{~cm} \mathrm{~s}^{-1}$, which is much less than the observed tidal velocities. The observed velocities must therefore be a baroclinic flow with oppositely directed flow in the 


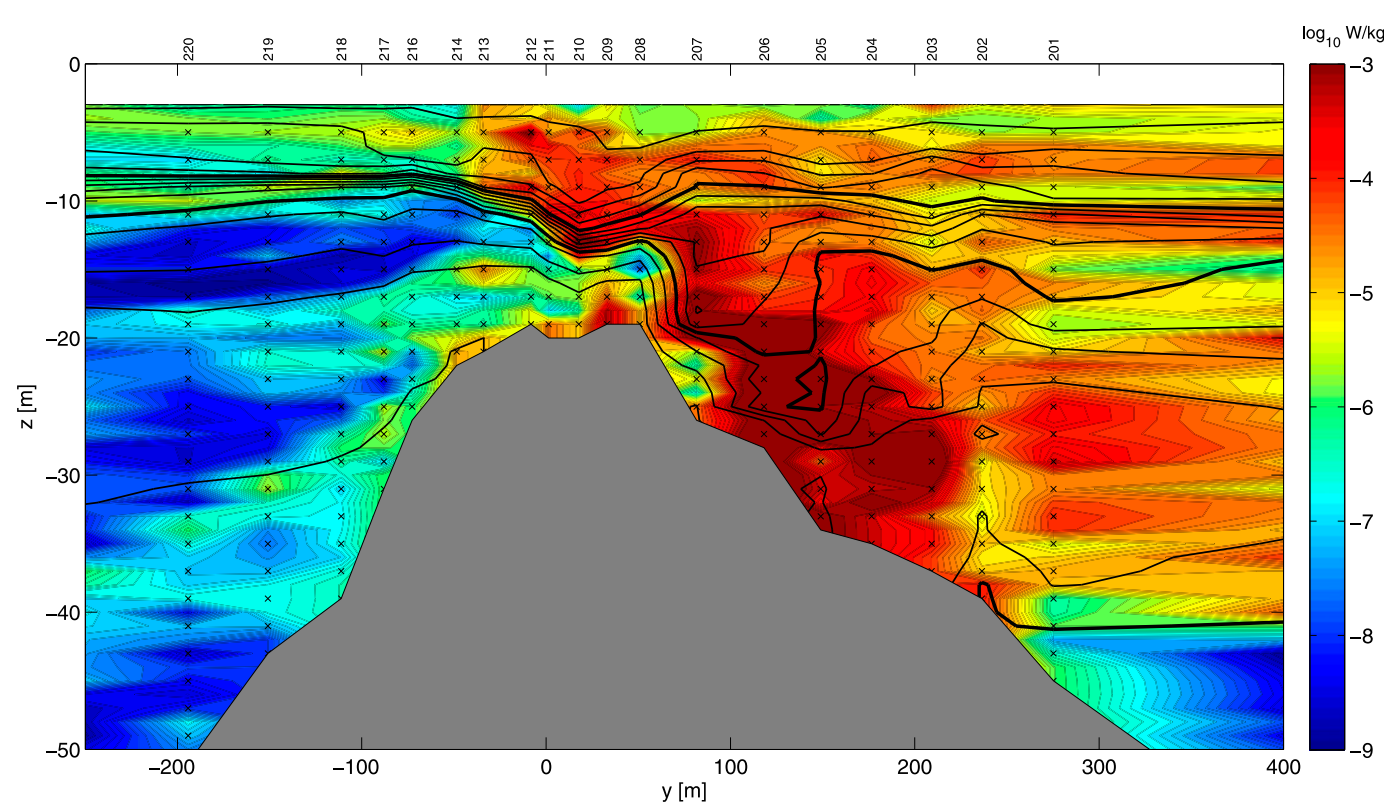

FIG. 4. Density contours drawn on top of dissipation rates for transect 9 . The density contour interval is $1 \mathrm{~kg} \mathrm{~m}^{-3}$, and every fifth contour is drawn with a bold line. The dissipation rates are shown on a logarithmic color scale. Profile numbers are indicated on top of the figure. Note that the high value at $20-\mathrm{m}$ depth between profiles 207 and 208 is an artifact produced by the interpolation.

two layers (above and below $10.5 \mathrm{~m}$ ). These kind of fluctuating baroclinic currents are commonly seen in the fjords around Skagerrak (e.g., Aure et al. 1996; Arneborg 2004).

\section{b. MSS transects}

MSS transects over the sill were taken during six subsequent flood tides (transects 1, 2, 3, 6, 7, 9, 14, and 15) and during two ebb tides (transects $4,5,10,11,12$, and 13), as indicated with gray shading in Fig. 3a.

Figure 4 shows transect 9 taken during an inflow. The isopycnals between 5- and 30-m depth outside the sill narrow into a 5-10-m-thick layer over the sill that dives down along the bottom inside the sill crest. About 100$200 \mathrm{~m}$ downstream of the sill, the isopycnals rebound abruptly from this layer and adjust to the downstream stratification. This happens progressively, starting with the uppermost isopycnal and ending with the lowermost, which seems to be a typical pattern for internal hydraulic jumps as it is also observed in other fjords (e.g., Farmer and Armi 1999; Klymak and Gregg 2004; Arneborg and Liljebladh 2009). The dissipation rates of turbulent kinetic energy remain small upstream and in the bottom layer on and behind the sill, roughly $10^{-9}$ to $10^{-8} \mathrm{~W} \mathrm{~kg}^{-1}$. In the rebounding region/hydraulic jump farther downstream, it increases dramatically to $10^{-4}$ to $10^{-3} \mathrm{~W} \mathrm{~kg}^{-1}$, and after the rebounding region, it decays slowly downstream. This is also similar to observations of the dissipation rate in Knight Inlet (Klymak and Gregg 2004) and Loch Etive (Inall et al. 2004).
A selection of transects during different phases of the tide is presented in Fig. 5. As may be seen, hydraulic jumps were observed with varying strength during most inflows and outflows, but not during all. Differences in the barotropic forcing cannot fully explain the occurrence of hydraulic jumps. For instance, the tidal forcing in transect 14 without a hydraulic jump (with a barotropic velocity over the sill of $14 \mathrm{~cm} \mathrm{~s}^{-1}$ ) is stronger than that in transect 1 when a strong hydraulic jump was present (with a barotropic velocity of $8 \mathrm{~cm} \mathrm{~s}^{-1}$ ) (Fig. 3a). By studying the salinity profiles $500 \mathrm{~m}$ inside and outside the sill, we see that in cases when hydraulic jumps occur, the upstream halocline is located clearly above the downstream halocline. When the downstream halocline is at the same level or above the upstream halocline, we do not see evidence of a hydraulic jump (Fig. 5). Furthermore, we note that hydraulic jumps during the ebb phase are missing at the beginning of the observational period and also missing during flood tide at the end of the period. The possible link to the change from mean inflow to mean outflow in the bottom layer is discussed in section 4 .

To investigate the variation in dissipation rates of turbulent kinetic energy across the channel, two transects across the channel about $100-200 \mathrm{~m}$ inside the Drøbak Sill were performed during an inflow (transect 8 and 10 in Fig. 3a). Data from transect 8 and 10 are shown in Fig. 6. During a strong inflow (transect 8), the horizontal variations across the channel are fairly small. At the end of the inflow (transect 10), the dissipation is 


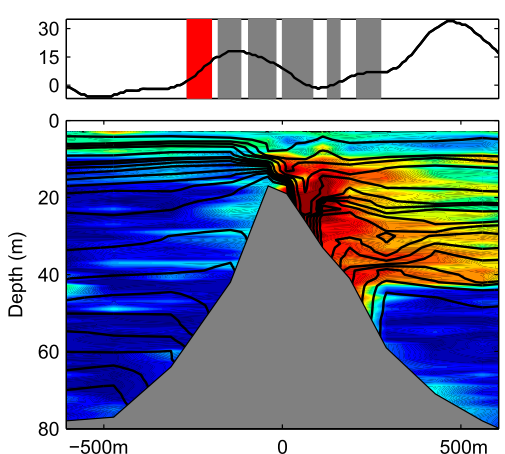

Section 2
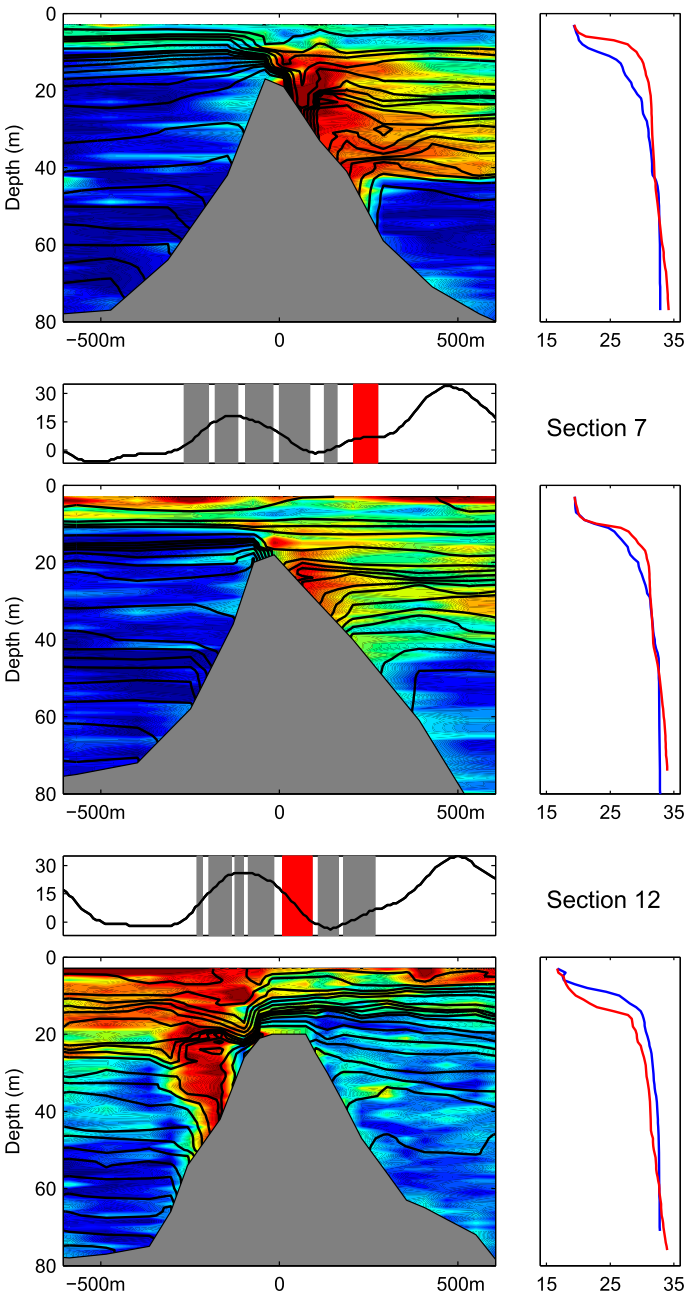

Section 7

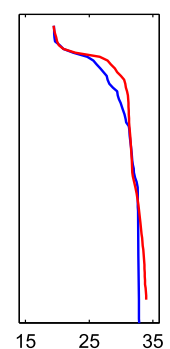

Section 12

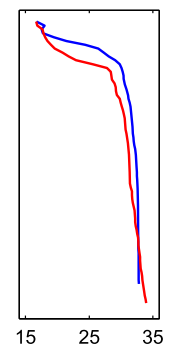

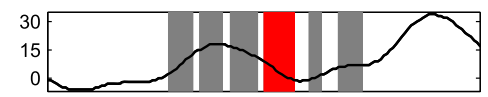
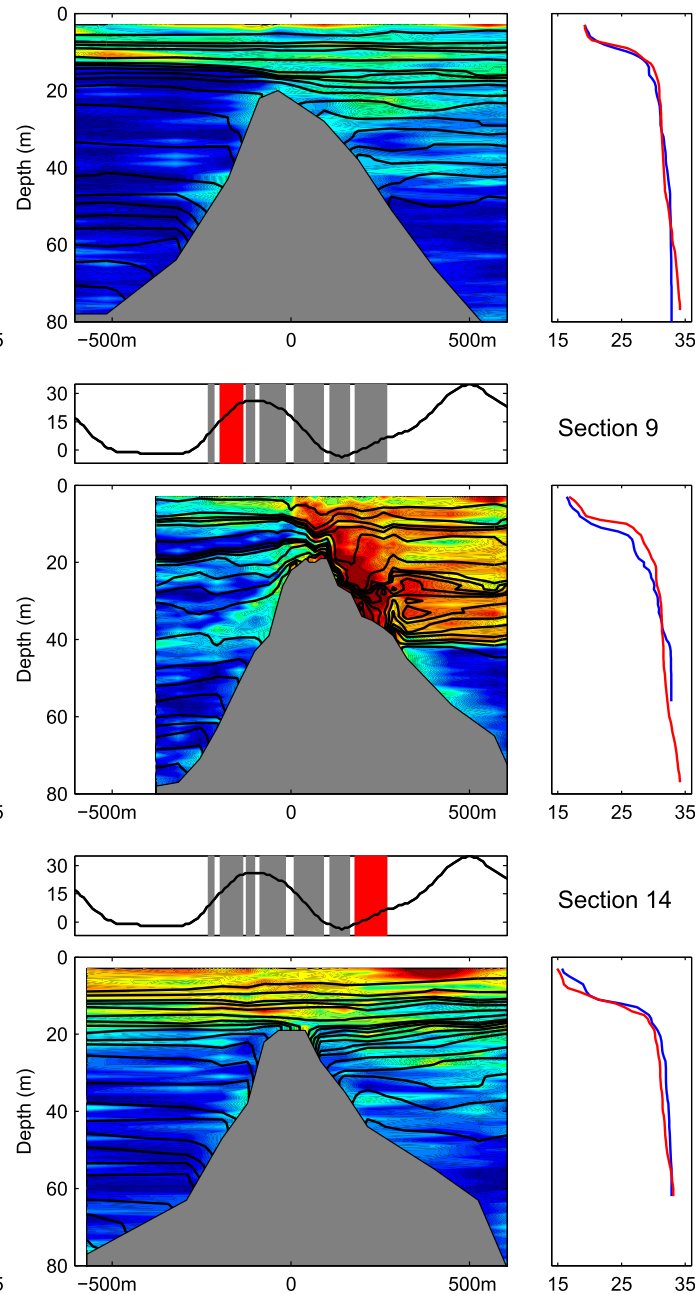

Section 14

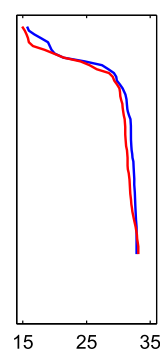

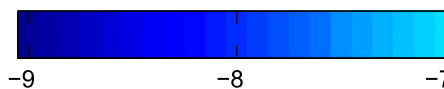

$-7$

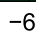

$-4$

$-3$

FIG. 5. Energy dissipation across the sill is shown on a logarithmic color scale $\left(10^{-9}\right.$ to $\left.10^{-3} \mathrm{~W} \mathrm{~kg}^{-1}\right)$ for six different transects. The density profiles $500 \mathrm{~m}$ inside the sill (blue line) and $500 \mathrm{~m}$ outside the sill (red line) are presented to the right of each transect. The time of the measurements within the tidal cycle is indicated by the red bar in the sea level displayed above each transect. The bottom profiles are obtained from the MSS and reflect local depths, not the thalweg.

weaker and patchy. When combining the two transects, there is no clear picture with large dissipation rates in some areas and small dissipation rates in others. This is different from the situations in Loch Etive and Knight Inlet, where most of the downstream dissipation was observed in a central jet and where much of the energy dissipation could be attributed to lateral eddy shedding (Inall et al. 2005; Klymak and Gregg 2001). The reason for the lack of a clear central jet north of the sill in the Oslofjord may be that the width of the channel is rather uniform because of the Drøbak Jetty, with no abrupt widening that can cause lateral separation. The situation may be different south of the sill, but there we have no cross-fjord transects.

\section{c. Moored ADCP data at the sill in 2009}

The density stratification at the sill is essentially two layered (Fig. 5), and we can therefore use two-layer hydraulics to analyze the flow. To calculate the composite Froude number (2), we need velocity and density observations at the sill. Fortunately, we have such data from a field experiment in 2009, and here we focus on a period with similar stratification and tidal amplitude as during the 2011 observations. The horizontal and 


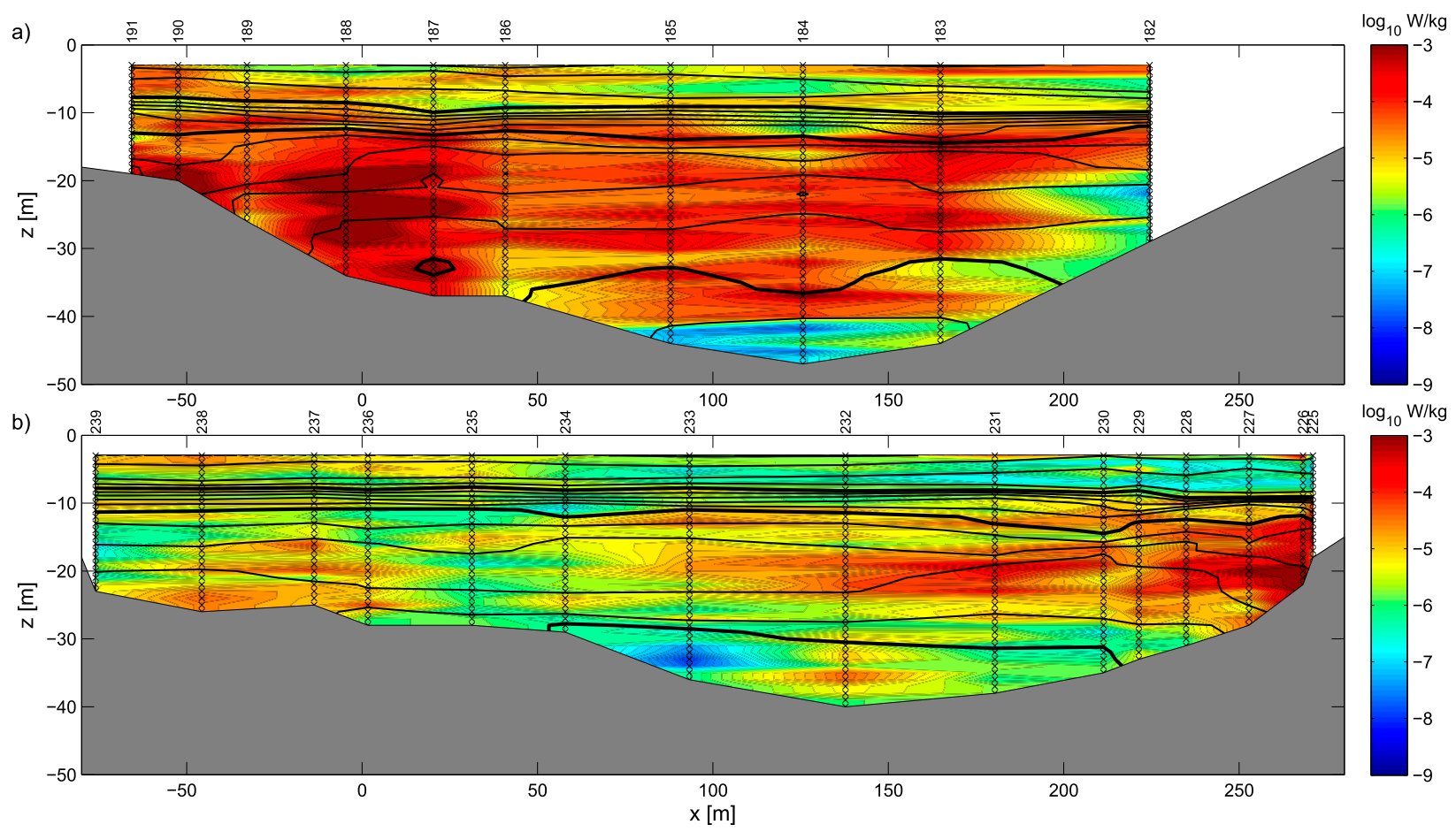

FIG. 6. Dissipation rates across the fjord (about $200 \mathrm{~m}$ inside the sill; see Fig. 2) are shown (a) at a strong inflow (transect 8) and (b) at the end of an inflow (transect 10). The color scale is dissipation on a logarithmic scale from $10^{-9}$ to $10^{-3} \mathrm{~W} \mathrm{~kg}^{-1}$. The contour lines are density surfaces with contour interval of $1 \mathrm{~kg} \mathrm{~m}^{-3}$, where every fifth contour is drawn with a bold line. The numbers on top of the figure are profile numbers.

vertical velocities just inside the sill crest (station S1; Fig. 2) showed strong bottom-enhanced velocities of up to $1 \mathrm{~m} \mathrm{~s}^{-1}$ during about 7 of 9 flood tides (Figs. 7a,c). During these situations, the mooring at S2 showed similar patterns in 2009 (Fig. 7b) as in 2011 (Fig. 3), with enhanced velocities in the depth range of $15-30 \mathrm{~m}$. From Fig. 7a, which shows the velocities both above and below the pycnocline, we conclude that there is a two-layer baroclinic flow superimposed on the barotropic flow.

To calculate the Froude number from the observations, we estimate that the thicknesses of the upper and lower layer are 12 and $11 \mathrm{~m}$, respectively (Fig. 7a), and that the densities of the upper and lower layers are 1014 and $1021 \mathrm{~kg} \mathrm{~m}^{-3}$, based on the CTD profiles from the area. The Froude numbers (2) and (3) can then be calculated from the estimated currents averaged over each layer. The results are presented in Fig. $7 \mathrm{~d}$ and illustrate that the composite Froude number is critical to supercritical during the flood tides with stronger currents in the lower layer and subcritical during the other flood tides and during ebb tides in a general weaker current in the lower layer.

During periods with composite Froude numbers larger than or equal to 1 , the vertical velocities (Fig. 7c) were negative at the bottom in accordance with a supercritical flow following the sloping bottom (e.g.,
Farmer and Armi 1999). We therefore conclude that these events are associated with hydraulic jumps.

We note that the mean flow below (above) 11-m depth was negative (positive) during the two to three tidal periods without hydraulic jumps, indicating that the baroclinic mean flow influences the hydraulic jumps consistent with the discussion in section $3 \mathrm{a}$ and in the introduction. Furthermore, this is in accordance with two-layer hydraulic theory for flow over a sill (e.g., Armi 1986), where it is the bottom-layer Froude number that dominates the composite Froude number over the sill crest, as mentioned above, and discussed further in section $4 \mathrm{a}$.

A challenge in this work has been the lack of simultaneous MSS profiles and ADCP measurements at the sill. Instead, the focus was on recording the response in the downstream current field at station S2. However, a correlation analysis of the simultaneous current measurements at stations S1 and S2 from 2009 show that the lower-layer velocity over the sill $v_{2}$ can be estimated from the measured velocity at station $\mathrm{S} 2$ with a rootmean-square error of $0.21 \mathrm{~m} \mathrm{~s}^{-1}$ (Fig. 8a). The observed currents at both stations can be seen in Fig. 7. When the lower-layer velocity over the sill is determined, the upper-layer velocity can be estimated from volume conservation, where we assume that the observed sea level fluctuations within the fjord are dominated by the 
a)
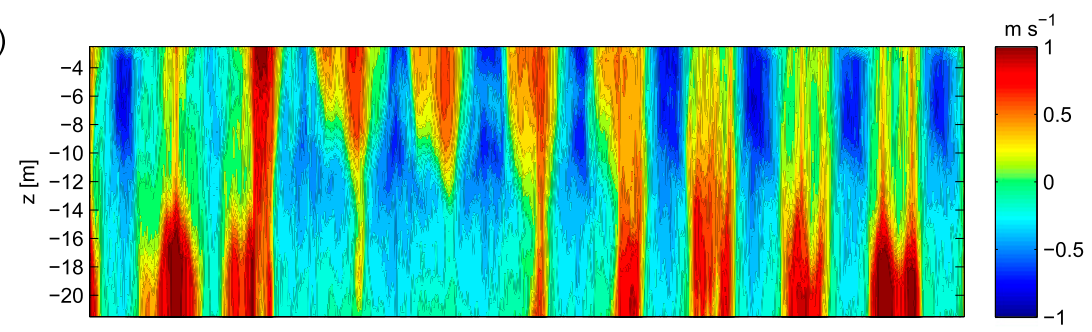

b)

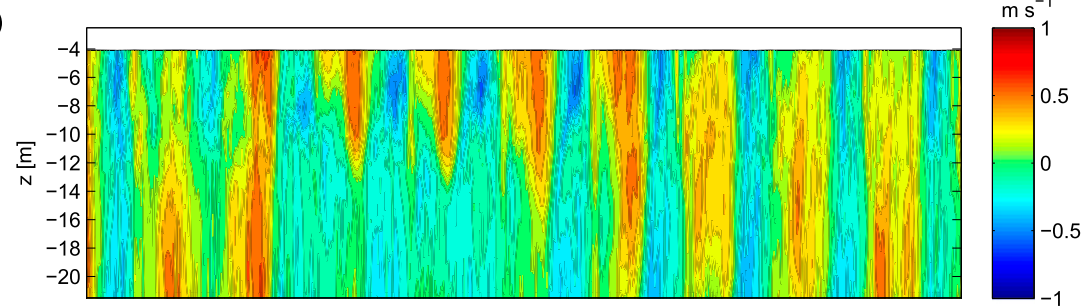

c)

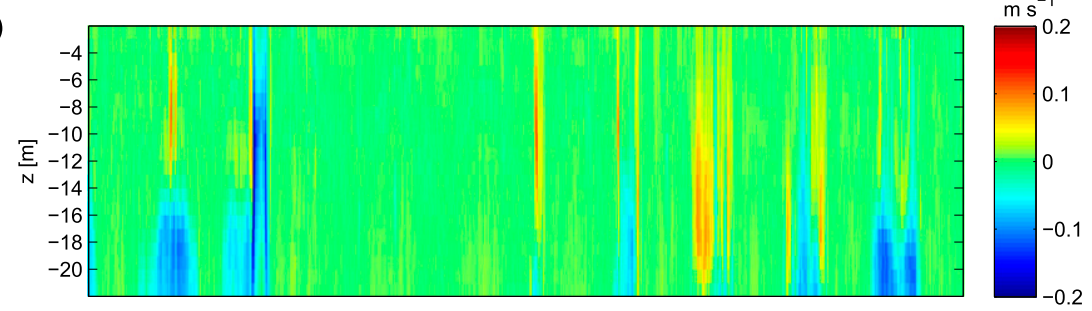

d)

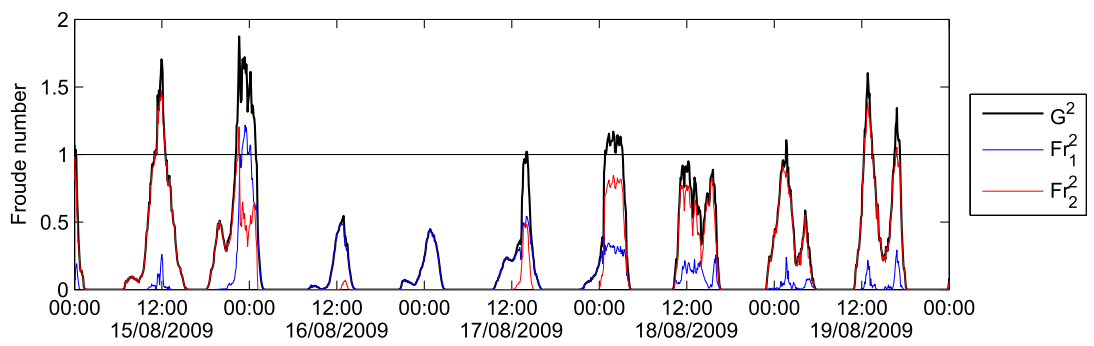

FIG. 7. (a) Horizontal current along the channel at station S1 in 2009. Red colors indicate currents into the fjord and blue colors indicate currents out of the fjord in $\mathrm{m} \mathrm{s}^{-1}$. (b) Horizontal current along the channel at station S2 in 2009. Red colors indicate currents into the fjord and blue colors currents out of the fjord in $\mathrm{m} \mathrm{s}^{-1}$. (c) Vertical velocity at station S1. Red colors indicate upward and blue colors downward velocities in $\mathrm{ms}^{-1}$. (d) The composite [(2)] and densimetric [(3)] Froude numbers are plotted for the same time period.

barotropic volume flux over the Drøbak Sill. The composite Froude number can then be estimated from (2) and (3) with a root-mean-square error of 0.23 (Fig. 8b).

\section{d. Integrating the dissipation}

The estimated volume-integrated dissipation rates within $500 \mathrm{~m}$ inside $E_{\text {in }}$ and outside $E_{\text {out }}$ the sill crest are presented in Table 1 . These are calculated by summing all dissipation rate estimates multiplied with density and representative volume for that bin. We did not find any systematic variation of dissipation rates across the width of the fjord (section 3b) and simply assume that the dissipation rates observed along the center line of the fjord are representative of the entire fjord width.
The uncertainties of these estimates were obtained from two transects taken across the channel just inside the sill (Fig. 6). For both transects the dissipation was integrated across the channel. Correction factors were calculated by dividing these results with results obtained by letting each of the profiles represent the entire transect. A Rayleigh distribution suitable for nonnegative quantities was fitted to the actual distribution of correction factors (Fig. 9). In the next step, each of the profiles in transects along the channel was multiplied by a random number with this distribution, and this procedure was repeated 300 times to obtain an adequate statistical basis. The standard deviations of the results were interpreted as error estimates. The results with error estimates are listed in Table 1. 

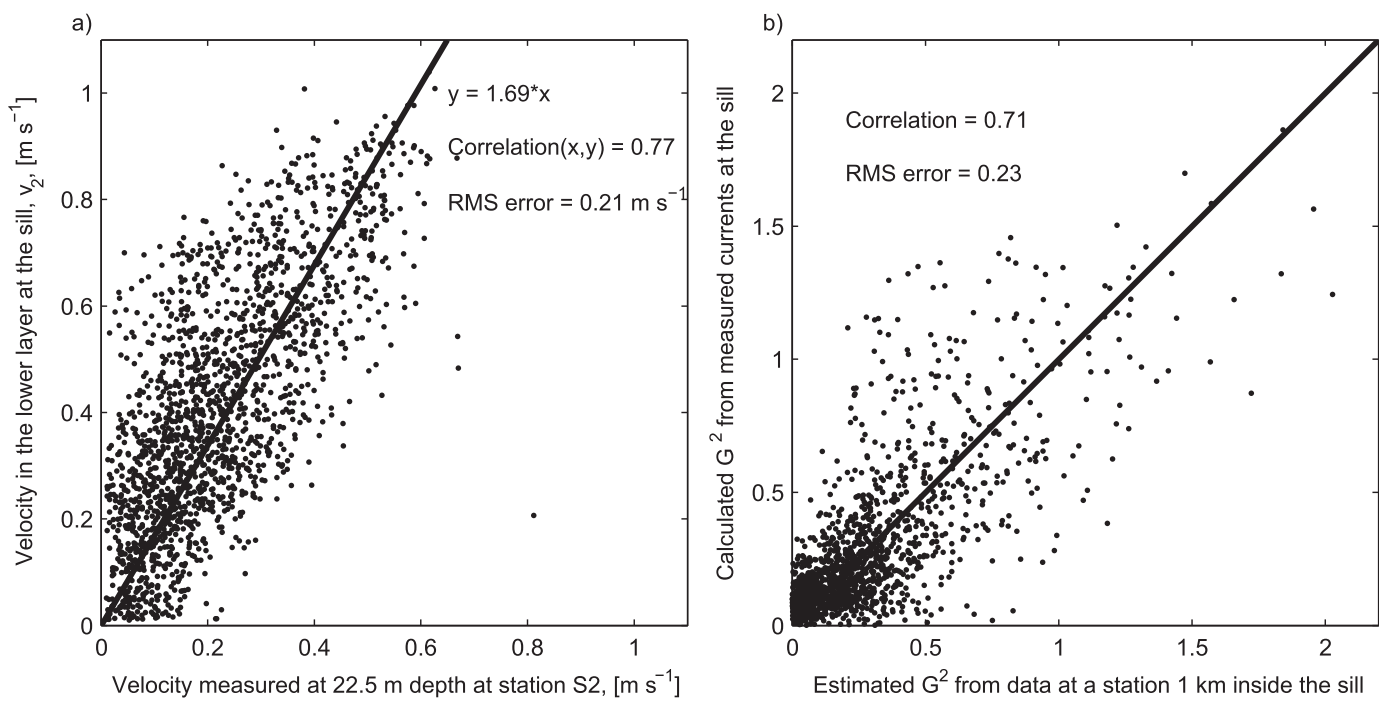

FIG. 8. (a) Correlation between the measured current at station S2 $1 \mathrm{~km}$ inside the sill and the measured current in the lower layer over the sill, station S1, based on data measured in August 2009. The $x$ axis shows the measured current at 22.5-m depth at station S2. The $y$ axis shows the measured current at S1 integrated over the depth range from $10.5 \mathrm{~m}$ to the sill depth. (b) Correlation between the composite Froude numbers calculated from estimated and measured velocities over the sill.

Inside the sill, the highest value was $3500 \pm 1500 \mathrm{~kW}$, the lowest value was $2.7 \pm 0.8 \mathrm{~kW}$, and the mean value was $660 \pm 290 \mathrm{~kW}$. At the outside, the largest value was $1500 \pm 560 \mathrm{~kW}$, the lowest value was $1.9 \pm 0.6 \mathrm{~kW}$, and the mean value was $160 \pm 64 \mathrm{~kW}$. The high value of $E_{\text {out }}$ was obtained during the only observed hydraulic jump outside the sill (transect 12). The Froude numbers, estimated as described in section $3 \mathrm{c}$, are drawn as a time series (Fig. 3c) above the results from Table 1 (Fig. 3d), and it is evident that in the cases where $E_{\text {in }}$ exceeds about $3000 \mathrm{~kW}$ it is probable that we have $G^{2}>1$. However, inaccuracy in the estimate of $G^{2}$ leaves some uncertainty whether or not the value actually exceeds 1 . The cases with very high values of integrated dissipation rates are all obtained during the presence of hydraulic jumps, which dominate the estimates of the mean dissipation rates. The mean value calculated above may be misleading because of the combination of an uneven distribution of measurements and dissipation rates that varies greatly with location and time. Thus, to obtain reliable mean values over a tidal cycle, it is necessary to correct biases from overrepresented tidal phases in the observations. A mean tidal cycle is obtained by averaging within $1.77-\mathrm{h}$ tidal phase bins, giving seven bins over a complete tidal cycle (Fig. 10).

TABLE 1. Overview of 368 MSS profiles in 15 transects. N is northbound, $\mathrm{S}$ is southbound, and A is across. Last column is theoretical estimates using (5).

\begin{tabular}{|c|c|c|c|c|c|c|c|}
\hline No. & Date & Start time $(\mathrm{UTC}+2)$ & End time $(\mathrm{UTC}+2)$ & Direction of vessel & $E_{\text {in }}(\mathrm{kW})$ & $E_{\text {out }}(\mathrm{kW})$ & $E_{B}(\mathrm{~kW})$ \\
\hline 1 & $20 \mathrm{Jun}$ & 1632 & 1750 & $\mathrm{~N}$ & $1200 \pm 480$ & $18 \pm 9.0$ & 2600 \\
\hline 2 & 21 Jun & 0843 & 1004 & $\mathrm{~N}$ & $3500 \pm 1500$ & $8.9 \pm 5.5$ & 2700 \\
\hline 3 & 21 Jun & 1026 & 1142 & $\mathrm{~N}$ & $1700 \pm 920$ & $1.9 \pm 0.6$ & 3300 \\
\hline 4 & 21 Jun & 1208 & 1339 & $\mathrm{~N}$ & $75 \pm 37$ & $3.3 \pm 1.5$ & 29 \\
\hline 5 & 21 Jun & 1400 & 1542 & $\mathrm{~N}$ & $2.7 \pm 0.8$ & $5.7 \pm 2.3$ & 25 \\
\hline 6 & 21 Jun & 1600 & 1712 & $\mathrm{~N}$ & $250 \pm 160$ & $3.1 \pm 1.3$ & 230 \\
\hline 7 & 21 Jun & 1808 & 1928 & $\mathrm{~S}$ & $120 \pm 55$ & $12 \pm 6.8$ & 390 \\
\hline 8 & 22 Jun & 0925 & 0944 & A & & & \\
\hline 9 & 22 Jun & 0957 & 1124 & $\mathrm{~S}$ & $1700 \pm 580$ & $64 \pm 25$ & 1700 \\
\hline 10 & 22 Jun & 1132 & 1217 & A & & & \\
\hline 11 & 22 Jun & 1217 & 1342 & $\mathrm{~S}$ & $9.2 \pm 2.1$ & $36 \pm 9.3$ & 15 \\
\hline 12 & 22 Jun & 1411 & 1549 & $\mathrm{~N}$ & $18 \pm 8.7$ & $1500 \pm 560$ & 930 \\
\hline 13 & 22 Jun & 1610 & 1716 & $\mathrm{~S}$ & $5.9 \pm 1.6$ & $410 \pm 200$ & 260 \\
\hline 14 & 22 Jun & 1734 & 1919 & $\mathrm{~S}$ & $13 \pm 3.9$ & $16 \pm 4.7$ & -400 \\
\hline 15 & 23 Jun & 0842 & 1136 & $\mathrm{~N}$ & $72 \pm 40$ & $14 \pm 5.7$ & 96 \\
\hline
\end{tabular}




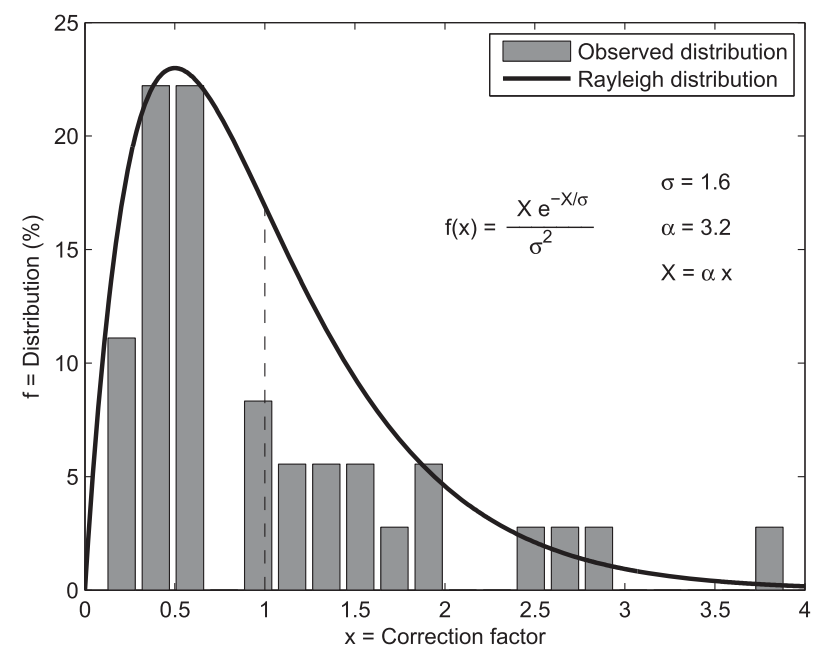

FIG. 9. Distribution of correction factors for sections 8 and 10. A continuous modified Rayleigh distribution, with a mean value of one, is fitted to the actual discrete distribution of correction factors.

The integrated dissipation averaged over the mean tidal cycle is $630 \pm 160 \mathrm{~kW}$ inside the sill and $160 \pm$ $58 \mathrm{~kW}$ outside the sill. Note that this is based on measurements during six inflows, while only two outflows were captured, which means that the data basis for the estimate of $E_{\text {out }}$ is sparse. It is also evident during both flood and ebb tides that the integrated local dissipation rates are two orders of magnitude larger on the downstream sides of the sill than on the upstream side, for cases when a hydraulic jump is observed (Table 1). This is consistent with the idea that the hydraulic jumps dominate the total dissipation rates near the sill in our observations.

\section{e. Bernoulli drop}

According to the results above, the integrated local dissipation rate above the Drøbak Sill is dominated by the internal hydraulic jump, which appears when the flow over the sill becomes critical. For jumps in layered flows, it is commonly assumed that the energy loss mainly takes place in the expanding layer (e.g., Baines 1995), and we therefore concentrate our following discussion on the lower layer. The Bernoulli function $B$ within a layer is defined as

$$
B=\frac{1}{2} v^{2}+\frac{p}{\rho}+g z,
$$

where $p$ is the pressure, and $v$ is the velocity along the channel. The total energy flux is given by $\rho v B$ (e.g., Baines 1995), and for a stationary flow, the integrated dissipation rate within a volume is therefore equal to the net flux of the product of the density and the Bernoulli function into that volume (e.g., Klymak and Gregg 2004).

Assuming that the flow is stationary and that the volume flux in the lower-layer $Q_{2}$ is constant within $500 \mathrm{~m}$
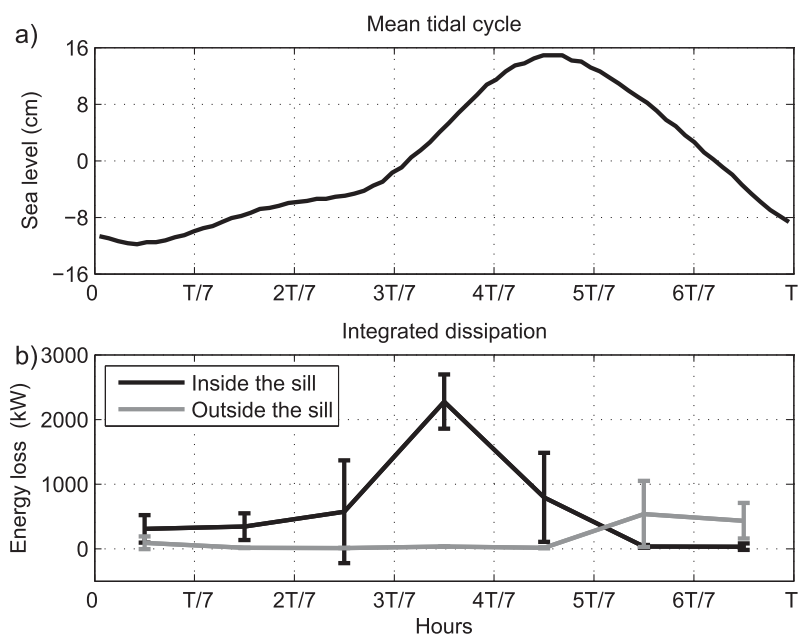

FIG. 10. (a) The mean tidal cycle of surface elevation. (b) The mean tidal cycle of integrated dissipation rates $E_{\text {in }}$ (black line) and $E_{\text {out }}$ (gray line). Error limits are indicated with vertical bars.

from the sill (i.e., neglecting mixing), the integrated dissipation in the lower layer can be estimated as

$$
E_{B}=-\rho Q_{2} \Delta B_{2}
$$

where $\Delta B_{2}$ is the change in the lower-layer Bernoulli function from $500 \mathrm{~m}$ outside the sill to $500 \mathrm{~m}$ inside the sill.

Estimates of the energy loss calculated from the Bernoulli drop are given in Table 1, which may be compared to integrated dissipation rates (cf. Fig. 11). These have been calculated by using volume flux estimates below $15 \mathrm{~m}$ at station S2 and horizontal pressure gradients in the depth range from 20 to $40 \mathrm{~m}$,

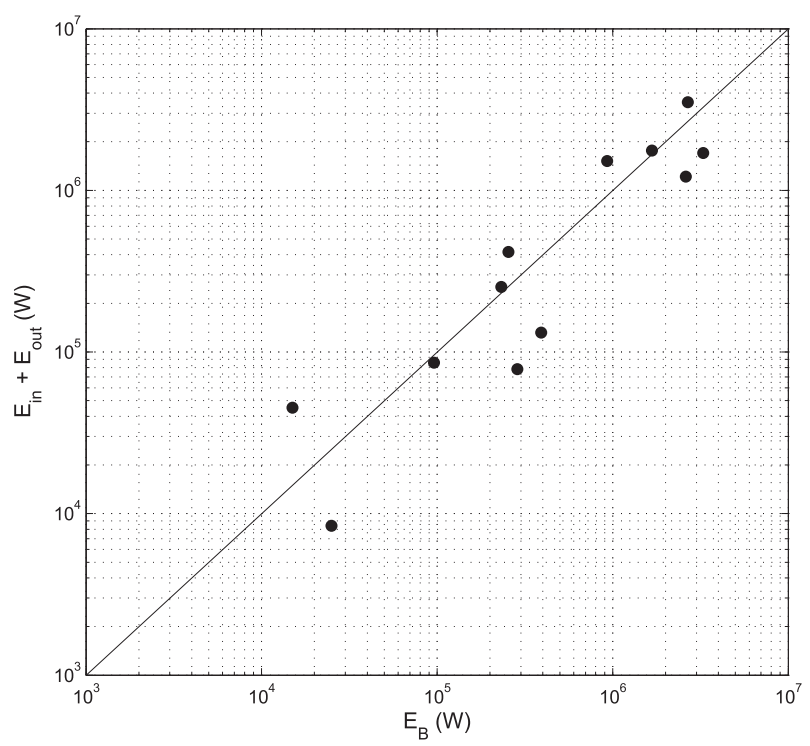

FIG. 11. Integrated dissipation is plotted as a function of the energy loss in the Bernoulli drop [(5)]. 
calculated from density profiles $500 \mathrm{~m}$ inside and outside the sill. In these calculations we assume that the energy loss in the upper layer is negligible, the velocity head difference is small compared to the pressure difference, and the lower-layer volume flux at S2 is equal to the bottom-layer flux over the sill. For further discussion of the method see Klymak and Gregg (2004).

The values of the estimates from the measurements and the Bernoulli drops are surprisingly similar (correlation coefficient of 0.87), given the large number of assumptions and uncertainties in the estimates, and this provides a certain amount of credibility both to the estimates and the assumptions. This also means that the local energy budget is relatively well closed, and there are no large energy sources or sinks that are not accounted for in the observations.

\section{f. Relation between bottom sill velocity and dissipation rates}

During situations where the lower layer is accelerated, especially when enhanced by mean baroclinic flow, this leads to hydraulic jumps that dominate the integrated dissipation rate above the sill. Thus, it is not surprising that we find a strong correlation between $E_{\text {in }}$ and the current measured below sill depth at station S2. The correlation coefficient between $E_{\text {in }}$ and the current measured at $22.5 \mathrm{~m}$ from station $\mathrm{S} 2$ in the third power is 0.99. Earlier it is shown that these measurements can be related to the flow in the lower layer over the sill. This empirical result can be expressed as

$$
E_{\mathrm{emp}}=C v_{2}^{3},
$$

where the proportionality factor $\mathrm{C}$ is $5.7 \pm 1.7 \times 10^{6} \mathrm{~kg} \mathrm{~m}^{-1}$. Klymak et al. (2010) derived an expression for the integrated dissipation in the case of linear stratification, where it is argued that it scales with the barotropic flow over the sill in the third power. In the limit of two-layer stratification, we find that the integrated dissipation is proportional to the flow in the lower layer to the third power. The result from (6) is plotted together with the observed $E_{\text {in }}$ in Fig. 3d, and the estimate from (6) is well within the error range of the observed values. We note that according to (6) the integrated dissipation reach well above $2000 \mathrm{~kW}$ during the unobserved strong inflow after transect 7 , but is close to zero in the strong inflow after transect 14 .

\section{Discussion}

\section{a. Influence of mean baroclinic flow on the presence and strength of hydraulic jumps}

As shown in section $3 \mathrm{~b}$, internal hydraulic jumps are present in some but not all flood and ebb tides, and this cannot be explained by differences in barotropic forcing alone. In the previous section, we found a strong correlation between the total dissipation rates near the sill and the energy loss in the lower layer estimated from the drop in the lower-layer Bernoulli function. In these calculations, the energy loss in the upper layer was assumed to be zero, and the change in the Bernoulli function was mainly caused by the interface being lower downstream than upstream.

The observations at Knight Inlet (Klymak and Gregg 2004) showed that the difference in upstream and downstream interface, also causing a Bernoulli drop in their case, was created by the blocking of the lower layer at the sill, resulting in accumulation upstream and divergence downstream. Blocking, and the associated asymmetric flow over the sill, is only possible if the flow is critical $\left(G^{2}=1\right)$ at the sill. Thus, a hydraulic jump and the associated energy loss and interface drop are only possible if the flow is strong enough to obtain critical flow at the sill.

The observed tidal-averaged baroclinic exchanges (Fig. 3b; section 3a) probably explain why hydraulic jumps and large energy losses are absent on one side of the sill and enhanced on the other during some tidal cycles. During the first four tidal cycles there is a mean inward flow in the bottom that increases the value of $G^{2}$ during flood and decreases it during ebb tides. Therefore, the flow is controlled during a larger fraction of the flood tide. The mean baroclinic two-layer flow must be caused by a mean difference in interface height over the sill. During flood tide the change in interface height caused by the tidal flow adds to the mean interface height difference, which increases the energy loss. During ebb tide the value of $G^{2}$ decreases because of the mean inflow in the lower layer; the interface difference caused by the tidal flow is opposite that of the mean flow, and the flow therefore never reaches critical flow at the sill. At the end of the observational period, the mean bottom-layer flow is outward, decreasing the value of $G^{2}$ during flood and increasing it during ebb tides. A reasonable explanation for the missing hydraulic jumps therefore is that the mean baroclinic exchange pushes the flow below the limit of a controlled situation during those occasions where hydraulic jumps are not present.

To support this conclusion, we investigate, using twolayer theory, the magnitude of the barotropic current at which the flow becomes critical at the sill for a given baroclinic current. The equations to solve are

$$
G^{2}=1
$$

where $G$ is given by (2), 


$$
\begin{aligned}
& v_{1}=\frac{q_{0}-q}{h_{1}} \text { and } \\
& v_{2}=\frac{q_{0}+q}{h_{2}},
\end{aligned}
$$

where $q_{0}$ and $q$ are the barotropic and baroclinic volume fluxes in deep water, and the Bernoulli equation

$$
\frac{1}{2}\left(v_{2}^{2}-v_{1}^{2}\right)-g * h_{1}=\text { constant }
$$

where we have used the rigid-lid approximation for the surface boundary condition. The quantity $g^{*}\left[=g\left(\rho_{2}-\rho_{1}\right) /\right.$ $\left.\rho_{1}\right]$ is the reduced gravity. Note that the barotropic volume fluxes in deep water are not barotropic over the sill.

The solution can be written in terms of the nondimensional variables $\mathrm{Fr}=q_{0} /(H-d) / c_{1}, \mathrm{Fr}_{\mathrm{bc}}=q /(H-$ $d) / c_{1}, h_{10} /(H-d)$, and $\mathrm{d} / \mathrm{H}$ :

$$
f\left(\mathrm{Fr}, \mathrm{Fr}_{\mathrm{bc}}, h_{10} /(H-d), d / H\right)=0,
$$

where $\mathrm{Fr}_{\mathrm{bc}}$ is the baroclinic Froude number, $h_{10}$ is the deep-water upper-layer depth, $H$ is the total water depth away from the sill, and $d$ is the sill height. The solution curves are shown in Fig. 12 for selected values of $h_{10} /$ $(H-d)$, and $d / H=0.8$. These curves may be seen as the outer limits for subcritical flow over the sill, since (7) is fulfilled along these lines. The dashed lines show when the upstream flow becomes critical. Examples relevant for the Oslofjord are indicated with black circles connected with lines, corresponding to a barotropic Froude number oscillating between \pm 0.45 . The relevant solution curves in this case are those for $h_{10}(H-d)=0.5$. For zero baroclinic mean flow, the flow at the sill becomes critical for $|\mathrm{Fr}|>$ 0.36 . For $\mathrm{Fr}_{\mathrm{bc}}=0.3$, corresponding approximately to the situation at the beginning of the observational period in 2011 with inward mean flow in the bottom layer, the flow is critical for $\mathrm{Fr}>-0.05$ and subcritical for $-0.62<\mathrm{Fr}<$ -0.05 . This corresponds well with the observed absence of a hydraulic jump during ebb tide in the Oslofjord during this period. According to this theory, hydraulic jumps start to appear during ebb tides, when the baroclinic Froude number drops below 0.11 . Our observations are not detailed enough to confirm this prediction, but the theory supports the hypothesis that the observed baroclinic mean flows can push the conditions beyond the limit when hydraulic jumps do not occur during the tidal phases when they are opposed by the bottom-layer baroclinic flow.

\section{b. Energy partition}

So far we have mainly discussed the dissipation rates near the sill. We know that there is also an energy flux away from the sill mediated by propagating internal waves (Staalstrøm et al. 2012). Thus, the question we

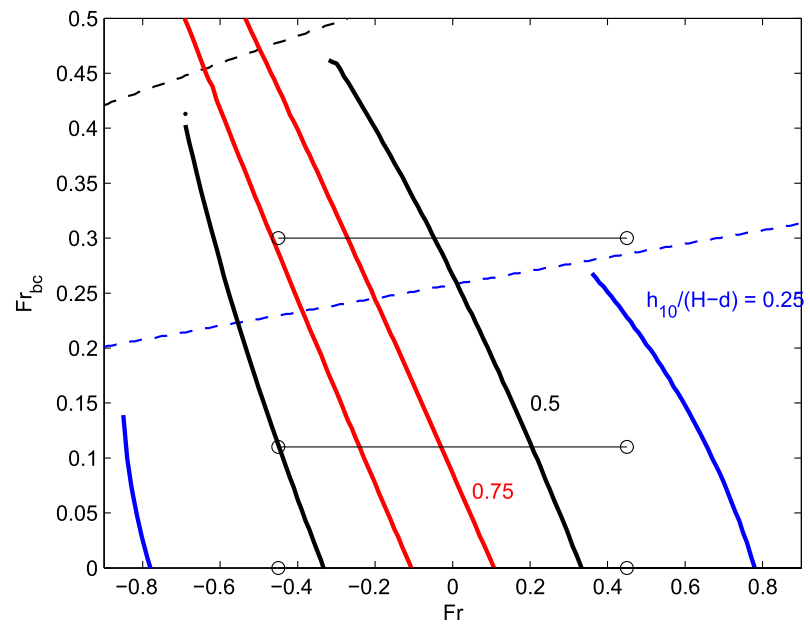

FIG. 12. Baroclinic Froude number $\operatorname{Fr}_{\mathrm{bc}}=q /(H-d) / c_{1}$ vs barotropic Froude number $\mathrm{Fr}=q_{0} /(H-d) / c_{1}$ for solutions with critical conditions at the sill (full lines), and upstream of the sill (dashed), sill height $d / H=0.8$, and upper-layer depth $h_{10} /(H-d)=0.25$ (blue), 0.5 (black), and 0.75 (red). Also shown are trajectories corresponding to mean baroclinic Froude number of $0,0.11$, and 0.3 and barotropic Froude number cycling between \pm 0.45 (black circles connected by lines).

pose is how the barotropic energy loss is partitioned between local energy loss and radiated energy that may cause mixing further into the fjord.

Staalstrøm et al. (2012) calculated the energy flux due to internal waves $\left(F_{\text {IW }}\right)$ into the fjord at station S2 from measurements of temperature, salinity, and currents during August 2009 with several methods. The method we trust most used a correlation term of baroclinic pressure and baroclinic velocity described by Kunze et al. (2002), giving $F_{\mathrm{IW}}=190 \pm 90 \mathrm{~kW}$. If we combine this estimate with the presently obtained results $E_{\text {in }}=630 \pm 160 \mathrm{~kW}$, we find that about $60 \%-90 \%$ of the total energy loss inside the Drøbak Sill dissipates within $500 \mathrm{~m}$ from the sill.

Our estimate of the barotropic energy dissipation near the sill is much higher than the $33 \%$ in the Canadian Knight Inlet (Klymak and Gregg 2004) and about the same as the $60 \%-80 \%$ in the Scottish Loch Etive (Inall et al. 2004). The Froude numbers equal 0.75 in Knight Inlet, 1.8 in Loch Etive, and only 0.45 in the Oslofjord. With these numbers it is surprising that the fraction of local dissipation in the Oslofjord is as high as in Loch Etive, which have much stronger currents relative to the stratification and much larger than the fraction at Knight Inlet, which is known to have powerful hydraulic jumps.

One important factor for internal wave generation is the vertical level of the pycnocline as compared to the height of the sill. In Loch Etive the upper layer extends all the way to the sill and therefore the bottom layer is blocked and internal tides have to be generated irrespectively of the hydraulics on the sill, whereas in the Oslofjord the bottom 
layer is not blocked unless there is critical conditions on the sill, meaning that first-mode internal waves may not always be generated (see the discussion in section 4a). This does, however, not explain why Knight Inlet is a more efficient wave generator than the Oslofjord.

Another factor that may explain the large fraction of local dissipation at the Oslofjord sill is that not only the tides cause the dissipation but also the mean baroclinic flow. Therefore, the fraction of barotropic tidal energy that dissipates locally is probably overestimated in this study. The interaction between the tidal flow and the mean baroclinic flow is highly nonlinear, and in the present study we see no way to separate these two energy sources. This must be left for future studies.

Although detailed studies of the hydraulic jumps in three fjords (Knight Inlet, Loch Etive, and the Oslofjord) have increased our understanding of the internal hydraulics and energetics near fjord sills, there are still many questions to answer regarding the relation between local energy loss and internal tide radiation and the influence of stratification, tidal flow strength, and sill geometry. We are presently looking into these issues with numerical and theoretical work.

Acknowledgments. This project was funded by the Norwegian Research Council (Project 184944). Lars Arneborg was supported by the Swedish Research Council through Grant 621-2008-2689. The field work would not have been possible without the assistance of the crew on board the R/V Trygve Braarud. Thanks are also due to Eyvind Aas and Lars Petter Røed for constructive discussions and suggestions.

\section{REFERENCES}

Afanasyev, Y. D., and W. R. Peltier, 2001: Reply to comment on the paper on breaking internal waves over the sill in Knight Inlet. Proc. Roy. Soc. London, A457, 2831-2834, doi:10.1098/ rspa.2001.0801.

Armi, L., 1986: The hydraulics of two flowing layers with different densities. J. Fluid Mech., 163, 27-58, doi:10.1017/S0022112086002197.

Arneborg, L., 2004: Turnover times for the water above sill level in Gullmar Fjord. Cont. Shelf Res., 24, 443-460, doi:10.1016/ j.csr.2003.12.005.

_ by baroclinic tidal flow near the sill of a fjord basin. J. Phys. Oceanogr., 39, 2156-2174, doi:10.1175/2009JPO4037.1.

Aure, J., J. Molvær, and A. Stigebrandt, 1996: Observations of inshore water exchange forced by a fluctuating offshore density field. Mar. Pollut. Bull., 33, 112-119, doi:10.1016/S0025-326X(97)00005-2.

Baines, P. G., 1995: Topographic Effects in Stratified Flows. Cambridge University Press, 482 pp.

Cummins, P. F., 2000: Stratified flow over topography: Time-dependent comparisons between model solutions and observations. Dyn. Atmos. Oceans, 33, 43-72, doi:10.1016/S0377-0265(00)00044-0.

Farmer, D. M., and R. A. Denton, 1985: Hydraulic control of flow over the sill in Observatory Inlet. J. Geophys. Res., 90, 90519068, doi:10.1029/JC090iC05p09051.
_ , and L. Armi, 1999: Stratified flow over topography: The role of small-scale entrainment and mixing in flow establishment. Proc. Roy. Soc. London, A455, 3221-3258, doi:10.1098/ rspa.1999.0448.

Inall, M., F. Cottier, C. Griffiths, and T. Rippeth, 2004: Sill dynamics and energy transformation in a jet fjord. Ocean Dyn., 54, 307-314, doi:10.1007/s10236-003-0059-2.

_, T. Rippeth, C. Griffiths, and P. Wiles, 2005: Evolution and distribution of TKE production and dissipation within stratified flow over topography. Geophys. Res. Lett., 32, L08607, doi:10.1029/2004GL022289.

Klymak, J. M., and M. C. Gregg, 2001: Three-dimensional nature of flow near a sill. J. Geophys. Res., 106, 22295-22311, doi:10.1029/2001JC000933.

_ and - 2003: The role of upstream waves and a downstream density pool in the growth of lee waves: Stratified flow over the Knight Inlet sill. J. Phys. Oceanogr., 33, 1446-1461, doi:10.1175/1520-0485(2003)033<1446:TROUWA>2.0.CO;2.

— Inlet sill. J. Phys. Oceanogr., 34, 1135-1151, doi:10.1175/ 1520-0485(2004)034<1135:TGTOTK >2.0.CO;2.

— S. Legg, and R. Pinkel, 2010: A simple parameterization of turbulent tidal mixing near supercritical topography. J. Phys. Oceanogr., 40, 2059-2074, doi:10.1175/2010JPO4396.1.

Kunze, E., L. K. Rosenfeld, G. S. Carter, and M. C. Gregg, 2002 Internal waves in the Monterey Submarine Canyon. J. Phys. Oceanogr., 32, 1890-1913, doi:10.1175/1520-0485(2002)032<1890: IWIMSC $>2.0 . \mathrm{CO} ; 2$.

Ledwell, J. R., E. T. Montgomery, K. L. Polzin, L. C. S. Laurent, R. W. Schmitt, and J. M. Toole, 2000: Evidence for enhanced mixing over rough topography in the abyssal ocean. Nature, 403, 179-182, doi:10.1038/35003164.

Lepland, A., R. Bøe, A. Lepland, and O. Totland, 2009: Monitoring the volume and lateral spread of disposed sediments by acoustic methods, Oslo Harbor, Norway. J. Environ. Manage., 90, 3589-3598, doi:10.1016/j.jenvman.2009.06.013.

Nash, J. D., and J. N. Moum, 2001: Internal hydraulic flows on the continental shelf: High drag states over a small bank. J. Geophys. Res., 106, 4593-4611, doi:10.1029/1999JC000183.

Prandke, H., and A. Stips, 1998: Test measurements with an operational microstructure-turbulence profiler: Detection limit of dissipation rates. Aquat. Sci., 60, 191-209, doi:10.1007/s000270050036.

Staalstrøm, A., E. Aas, and B. Liljebladh, 2012: Propagation and dissipation of internal tides in the Oslofjord. Ocean Sci., 8, 525-543, doi:10.5194/os-8-525-2012.

Stacey, M. W., 1984: The interaction of tides with the sill of a tidally energetic inlet. J. Phys. Oceanogr., 14, 1105-1117, doi:10.1175/ 1520-0485(1984)014<1105:TIOTWT > 2.0.CO;2.

Stashchuk, N., M. Inall, and V. Vlasenko, 2007: Analysis of supercritical tidal flow in a Scottish fjord. J. Phys. Oceanogr., 37, 1793-1810, doi:10.1175/JPO3087.1.

Stigebrandt, A., 1976: Vertical diffusion driven by internal waves in a sill fjord. J. Phys. Oceanogr., 6, 486-495, doi:10.1175/ 1520-0485(1976)006<0486:VDDBIW >2.0.CO;2.

_ 1999: Resistance to barotropic tidal flow in straits by baroclinic wave drag. J. Phys. Oceanogr., 29, 191-197, doi:10.1175/ 1520-0485(1999)029<0191:RTBTFI >2.0.CO;2.

_ and J. Aure, 1989: Vertical mixing in basin waters of fjords. J. Phys. Oceanogr., 19, 917-926, doi:10.1175/1520-0485(1989)019<0917: VMIBWO $>2.0 . \mathrm{CO} ; 2$.

Tryggestad, S., 1974: A survey of current conditions at Brenntangen and tides in the Oslofjord (in Norwegian). University of Oslo Tech. Rep., 120 pp. 